\title{
Key Trends in Institutional Changes Under Sustainable Development
}

\author{
Olga Karpova ${ }^{1, *}$, Inna Pevneva ${ }^{2}$, Irina Dymova ${ }^{3}$, Tatiana Kostina ${ }^{4}$, and Sergey $\mathrm{Li}^{5}$ \\ ${ }^{1}$ Kemerovo institute (branch) of Plekhanov Russian University of Economics, Department of \\ Economic Security, Accounting and Audit, 650992 Kuznetsky pr.39, Kemerovo, Russia \\ ${ }^{2}$ Kemerovo institute (branch) of Plekhanov Russian University of Economics, Department of \\ Humanities, 650992 Kuznetsky pr.39, Kemerovo, Russia \\ ${ }^{3}$ T.F. Gorbachev Kuzbass State Technical University, Department of Management Accounting and \\ Analysis, 650000 Vessennyaya st., 28, Kemerovo, Russia \\ ${ }^{4}$ Kemerovo institute (branch) of Plekhanov Russian University of Economics, Department of \\ Management and Business Technology, 650992 Kuznetsky pr.39, Kemerovo, Russia \\ ${ }^{5}$ Kemerovo institute (branch) of Plekhanov Russian University of Economics, Department of \\ Information technology and Applied Mathematics, 650992 Kuznetsky pr.39, Kemerovo, Russia
}

\begin{abstract}
The article is devoted to the consideration of the essential problems of accounting institution formation under the sustainable development of the country and the region. The research is based on the key research the field of the intuition economics and considers the trends of institutional changes including incremental, evolutionary and revolutionary. Approaches to the analysis of institutions are presented as well. The first approach states that economic efficiency is guaranteed by newly emerging institutions. The second approach involves certain internal and external incentives for changing institutions. Whereas the third approach insists on considering institutional changes to be the relation of individual economic entities to institutional innovations in terms of the net benefit from their implementation. The conclusion draws the leading role of the state in the process of the emergence and further development of newly created institutions focusing on the fact that not every change leads to greater efficiency. Thus it is crucial to consider the previous background of institutions' development at implementing changes in accounting and control.
\end{abstract}

\section{Introduction}

To develop a real sustainable development policy it is vital to take into account the interconnection and interdependence of all components, that is economic, social and environmental. Traditional instruments of economic analysis do not allow organizations to reliably determine the efficiency. Currently we see rather favorable conditions for the further improvement of accounting in the field of sustainable economic development as normative legal acts covering most accounting objects have come into effect.

\footnotetext{
${ }^{*}$ Corresponding author: oskarp@yandex.ru
} 
Nevertheless, Russian institutional environment and, accordingly, the region's environment continues its formation. Under the current economic conditions it is very important to develop institutions which will contribute to the growth of the economy. Undoubtedly such are the institute of accounting and the institute of control. The institutional economics theory defines accounting and control as economic institutions that fully correspond to this theory.

The sustainable development of an enterprise depends on the sustainable condition of the enterprise itself as an integral element in the external environment and the stability of its internal processes. Sustainable development of an enterprise is a process of permanent internal and external changes in which the use of all types of resources including investment, scientific and technological development, innovations and new technologies, HR and improving the quality of knowledge capital as well as the development of social institutions are coordinated with each other. They are all aimed at increasing the present and future potential of the enterprise, meeting its needs and achieving strategic goals. Thus, the principles of sustainable development are thoughtful management, harmony of the enterprise and the environment, the development of high technologies oriented to the environmental values.

As the research shows there is a large number of scientific works devoted to the analysis of institutional changes. This is due to the fact that institutional changes are an important condition for highly effective economic development. Traditionally, institutional changes mean the emergence of new rules with corresponding mechanisms for their implementation which substitute the old ones. Changes in institutions are related to the fact that the values that used to ensure their existence change as well come into conflict with other values and institutions [1-5, 11-14].

The analysis of institutional changes is good to start with considering formal and informal rules that determine the system of institutions, namely the institution of accounting and the institution of control. Due to the action of formal and informal institutions a stable institutional structure is achieved. Stability of the institutional structure of society gives us a feeling of comfort and confidence in our actions. However, despite the stability of institutions there is no guarantee that the institutions we rely on are effective.

\section{Materials and Methods}

Today the problem of the efficiency of the institute is one of the most essential in the field of research of institutional dynamics. Typically, changes in institutions happen due to the fact that over time the values that condition their existence change or they themselves may come into conflict with other institutions, as well as values. Stable institutions are also subject to change, but for the most part development takes place through insignificant increments that are permanent, although at times revolutionary changes in the institutional structure of society occur as well.

There are the following types of institutional changes that are described in the economic literature. Incremental institutional changes that happen due to the consolidation of informal norms and rules in small groups. Evolutionary institutional changes presuppose a gradual consolidation of informal norms as generally accepted in the formal rules of the relevant institution. Revolutionary institutional changes manifest themselves in the exogenous borrowing of the institute or their "import".

Some researchers miss the incremental institutional changes focusing on endogenous and exogenous changes. As mentioned, endogenous changes are carried out through evolutionary changes in existing norms and rules and exogenous institutional changes are radical and manifest themselves when importing institutions. It should be noted that the import of institutions does not always lead to an increase in production efficiency or to an accelera- 
tion in the rates of economic growth. Evolutionary changes are studied within the framework of the mainstream theory [6-7].

\section{Discussion}

The evolutionary path of change is less painful and more effective as it reduces the costs of updating changes to the relevant institutional environment. Nevertheless, evolution does not guarantee the dependence on the previous direction of development, the constant reproduction of knowledge aimed at maximizing the possible gains precisely in the existing institutional matrix that is a radical change in the institutions necessary for the withdrawal of society from stagnation and economic decline. It can't reduce transaction costs in the economy for such a short time period. Evolution does not reject changes of a qualitative nature, but refers to their mandatory historical dependence.

Changes in institutions are usually considered in the context of the three-levelled institutional organization of the economy. The levels of institutional organization are institutional order, institutional environment and institutional arrangement.

Targeted changes predominate at the level of the institutional structure which is primarily a formal institutional constraint. Changes at the level of the institutional structure of accounting are observed quite often in modern Russia. Infinite amendments to the existing normative legal acts on tax and accounting make it very difficult to focus in formal rules and create a favorable ground for the use of illegal informal rules.

The main reason for the change is the pressure of the institutional environment. The conflict between the institution and the environment in which they are function gives an incentive to activate one or several types of institutional isomorphism to restore conformity.

At present there are different opinions on the issue of institutional changes. We would like to focus on three basic approaches to the analysis of institutional changes.

The first approach ensures that high economic efficiency is guaranteed only by newly emerging institutions, and the prerequisites for their emergence presuppose previous changes in various areas from population dynamics to the technology development. The state as well as political processes in this case are inactive.

The second approach involves certain incentives for changing institutions, both internal and external. The logic of this approach was set out by D. North, who described the following stages. The emergence of new technologies is driven by changes in the level of knowledge; new technologies change relative prices of resources; new price levels create incentives for owners to transform ownership; the emergence of rules allowing to maximize the value of using these rules, lead to new price levels; non-zero transaction costs in the political market prevent possible institutional changes from being realized [8].

The authors of the third approach state that institutional changes are considered to be the relation of individual economic entities to institutional innovations in terms of the net benefit from their implementation [9].

Besides, the institutional economy speaks about the Harold Demsets scheme changes. Demsetz believes that the source of change is external shock which leads to a change in relative prices. The change in property rights is aimed at the effective use of resources and technologies. And most importantly it is assumed that the process of change is cost-free and is not related to the active actions of the state and stakeholding groups and organizations. This scheme of changes, in our view, can refer to the revolutionary type of institutional change. Armen Alchian put forward a "naive" theory of institutional changes holding the view that only effective institutions survive in the course of competition. This theory can refer to the evolutionary type of institutional change [10]. 
The above mentioned approaches to the essence of institutional changes have one common component - the state, which plays a decisive role in the process of the emergence and further development of newly created institutions.

The institutional changes that restore economic efficiency in the economy or contribute to its achievement include changes in relative prices. Such changes undoubtedly relate to the processes of globalization, the tendency of international integration, the growth of international cooperation and trade and, as a result, the transition to international financial reporting standards through the convergence and harmonization of national accounting systems. New relative prices create new opportunities for income generation by Russian companies, which in turn require appropriate institutional changes.

In addition, new technological opportunities entail the need to develop methods for accounting for new objects and new transactions, which in turn lead to institutional changes. Such objects can the accounting means of automation, a brand, web sites, scientific and technical development, advertising etc. These accounting objects are not a luxury but a necessity of modern companies for successful work and further promotion on the market. Thus, accounting is changing in order to reflect the company's attitude to innovation, the impact of risks and costs, obligations and the degree of liability associated with innovation. In connection with the advent of new technologies in the accounting organization we see changes in tastes and preferences. Lenders and investors today require for decision-making an extensive data and information of a different nature that can be easily and quickly generated through automated accounting systems.

It should be noted that in some cases, institutional changes lead to increased efficiency, in other cases changes play a redistributive role. There is also a case where there is a decrease in economic efficiency. The most common is the redistributive version of institutional changes. Hence, all the institutions can be hypothetically divided into three groups: increasing the efficiency of the economic system, neutral and reducing the efficiency of the economic system. In the framework of neoinstitutional analysis institutions that maximize social wealth are recognized as effective. However in Russia we see a paradoxical situation when the introduction of formal effective market institutions is accompanied by a decline in the efficiency of the economic system functioning. Explanation of this phenomenon should be sought in the mismatch of formal and informal institutions that together represent an institutional environment.

\section{Conclusion}

Institute of accounting and control can be attributed to institutions that increase the efficiency of the country's economic system. Despite the various institutional changes in Russia, the institutions of the command economy have firmly established themselves in the Russian economic system. Besides, the basic institutions inherent to a planned economy continue to exist today. Undoubtedly, such institutions include accounting and control.

All in all, the state plays a decisive role in the process of the emergence and further development of newly created institutions. Changes in the accounting and control institution are of an evolutionary nature and increase the efficiency of the economic system of the country. Implementing institutional changes in accounting with the aim of building an effective model, it is necessary to take into account the historical background and development of institutions.

\section{References}

1. D. Dequech, J. Econ. Iss. 36:2, 565-572 (2002) 
2. G.M. Hodgson, J. Econ. Iss. 34:2, 317-329 (2000)

3. M. Rutherford, J. Econ. Persp.15:3, 173-194 (2001)

4. M. Rutherford, Institutions in economics: the old and the new institutionalism (Cambridge University Press, Cambrige, 1996)

5. T. Lawson, Evol. Inst. Econ. Rev. 2:1, 7-20 (2005)

6. R.R. Nelson, S.G. Winter, An evolutionary theory of economic change (Harvard university press, Harvard, 2009)

7. J. Schumpeter, U. Backhaus, The theory of economic development (McGraw-Hill, New York, 2003)

8. D.C North, M.C. Brinton, V. Nee, The new institutionalism in sociology (McGrawHill, New York, 1998)

9. F. Toboso, Institutional arrangements matter for both efficiency and distribution: Contributions and challenges of the New institutional Economics (Springer, Berlin, 2011)

10. A.A. Alchian, H. Demsetz, Amer. Econ. Rev. 62:5, 777-795 (1972)

11. S. Tang, A general theory of institutional change (Routledge, London, 2017)

12. E. Brousseau, P. Garrouste, E. Raynaud, J. Econ. Behav.Org. 79:1, 3-19 (2011)

13. L.J. Alston, Emp. Stud. Inst. Chan. 10, 25-30 (1996)

14. G.M. Hodgson, New Polit. Econ. 6:2, 245-253 (2001) 
